\title{
Dietary Folate Equivalent
}

National Cancer Institute

\section{Source}

National Cancer Institute. Dietary Folate Equivalent. NCI Thesaurus. Code C68511.

A term used to describe the Recommended Dietary Allowance of folate; the term accounts for the easier absorption of folate in supplements and fortified foods as compared with the absorption of folic acid found naturally in foods. One Dietary Folate Equivalent $(\mathrm{DFE})=1$ microgram food folate $=0.6$ microg ram folic acid from supplements and fortified food. 